\title{
Double-diffusive mixed convection in a lid-driven cavity with non- uniform heating on sidewalls
}

\author{
S SIVASANKARAN $^{1, * \mathbb{O}}$, S S ANANTHAN ${ }^{2}$, M BHUVANESWARI ${ }^{1}$ and A K ABDUL HAKEEM ${ }^{3}$ \\ ${ }^{1}$ Department of Mathematics, King Abdulaziz University, Jeddah 21589, Saudi Arabia \\ ${ }^{2}$ Department of Mathematics, Erode Sengunthar Engineering College, Thudupathi 638057, India \\ ${ }^{3}$ Department of Mathematics, Sri Ramakrishna Mission Vidhyalaya College of Arts and Science, \\ Coimbatore 641020, India \\ e-mail:sd.siva@yahoo.com
}

MS received 6 June 2016; revised 22 January 2017; accepted 30 April 2017; published online 11 November 2017

\begin{abstract}
The effect of sinusoidal heating on double-diffusive mixed convective flow with heat and mass transfer in a lid-driven square cavity is numerically investigated. The horizontal walls of the cavity are adiabatic and impermeable. Sinusoidal boundary temperatures and concentrations are imposed along the left and right sidewalls of the cavity. The governing unsteady equations for continuity, momentum, energy and species transfer are solved using the finite-volume method. The numerical solutions are computed for various parameters such as the Richardson number, amplitude ratio, buoyancy ratio and phase deviation. The obtained results are discussed in detail under different combinations of the pertinent parameters.
\end{abstract}

Keywords. Mixed convection; double diffusion; non-uniform heating; lid-driven cavity.

\section{Introduction}

Combination of both free and forced convection is generally termed as mixed convection. Mixed convection in liddriven cavities has been studied by many researchers by moving either the top wall or the sidewall of the cavity with constant or oscillating velocities. Mixed convection occurs in a wide variety of applications, including cooling of electronic devices, furnaces, lubrication technologies, chemical processing equipment, drying technologies, solar energy storage and atmospheric flows [1,2]. The heat and mass transfer occurs concurrently and it leads to a complex fluid motion that is called double-diffusive convection. Double-diffusive convection has been the focus of an exhaustive research due to its importance in various engineering and geophysical problems [3]. It involves wide range of scientific and environmental fields such as solute intrusion in sediments in coastal environments, nuclear waste disposals, contaminant transport in ground water, chemical processes and species transport through biological membranes.

Joly et al [4] discussed Soret-driven thermosolutal convection in a vertical enclosure. It is found that the Soret effect is maximum when the Lewis number tends to zero. Sezai and Mohamad [5] numerically analysed double-diffusive convection in a cubic enclosure with opposing temperature and concentration gradients. It is found that the

*For correspondence average Nusselt and Sherwood numbers are decreased on increasing the buoyancy ratio from zero in the negative direction. Chamkha and Al-Naser [6] numerically studied hydro-magnetic double-diffusive convection in a rectangular enclosure with opposing temperature and concentration gradients. They found that the heat transfer and fluid circulation are reduced by increasing the magnetic field. AlAmiri et al [7] analysed mixed convection in a square liddriven cavity under the combined buoyancy effects of thermal and mass diffusion. Sivasankaran et al [8] found from a study on double-diffusive convection of cold water in a porous cavity that the convective heat and mass transfer rate are significantly affected by the presence of density maximum.

Teamah [9] investigated double-diffusive natural convection in a rectangular enclosure in the presence of magnetic field and heat source. He observed that the average Nusselt number is increased when the heat sink is present while the average Nusselt number is decreased in the presence of heat source. Bhuvaneswari et al [10] carried out a numerical study on double-diffusive mixed convection with a Soret effect in a two-sided lid-driven cavity. They showed that the heat and mass transfer rates are reduced if both walls are moving in the same direction, while heat and mass transfer rates are enhanced if the walls are moving in the opposite direction. Ismael and Chamkha [11] numerically examined mixed convection in lid-driven trapezoidal cavities with an aiding or opposing sidewall. They found that the behaviour of Nusselt number is different from that 
of Richardson number depending on the direction of the lid. Wang et al [12] numerically investigated coupling-diffusive effects on thermosolutal buoyancy convection in a horizontal cavity. They found that the heat and mass transfers of thermosolutal convection are enhanced when the Rayleigh number or buoyancy ratio is increased.

In recent years, convection in enclosures with various thermal boundary conditions is of interest for several researchers. In particular, the cases of non-uniform boundary temperature distributions on either one sidewall or on both sidewalls have also been examined. Saeid and Yaacob [13] numerically studied the natural convection in a square cavity with spatial sidewall temperature variation. They found that the average Nusselt number changes sinusoidally with increasing wave number. Further, the maximum average Nusselt number occurs at wave number $k=0.7$ for all Rayleigh numbers. Basak et al [14] carried out a numerical study to explain the effects of non-uniformly heated wall(s) on natural convection flow in a square porous cavity. They observed that the bottom wall with non-uniform heating produces better heat transfer rate at the centre of the bottom wall than the uniform heating for all values of Rayleigh numbers.

Deng and Chang [15] numerically investigated natural convection in a rectangular enclosure with sinusoidal temperature distributions on both sidewalls. They revealed that the natural convection in enclosures with two sinusoidal temperature distributions on the sidewalls is superior to that with a single sinusoidal temperature profile on one sidewall. Sivasankaran et al [16] numerically studied the mixed convection in a lid-driven cavity with non-uniform heating on both sidewalls. They found that the average Nusselt number increases on increasing the amplitude ratio. Bhuvaneswari et al [17] numerically analysed magnetoconvection in an enclosure with non-uniform heating on both sidewalls. They found that the heat transfer rate is increased on increasing the amplitude ratio. Sivasankaran et al [18] numerically studied the hydro-magnetic combined convection in a lid-driven cavity with sinusoidal boundary conditions on both sidewalls. They concluded that increasing the Hartmann number results in the decrease of the total heat transfer rate. Aswatha et al [19] numerically investigated the buoyancy driven heat transfer in cavities subjected to thermal boundary conditions at bottom wall. They obtained that the average Nusselt number for the case of uniform bottom wall is more than that of sinusoidally and linearly varying temperature profile.

Singh et al [20] analysed the effect of isothermal and non-isothermal heating on visualization of heat transport during natural convection in a tilted square cavity. It is found that the non-uniform heating provides larger heat transfer rates at the centre of the bottom wall than the uniform heating for all parameters. Sivasankaran and Pan [21] found from the study on mixed convection in a porous lid-driven cavity with non-uniform heating on both sidewalls that the average Nusselt number increases on increasing the amplitude ratio. Raji et al [22] revealed the fact that periodic cooling is used to enhance the heat losses in comparison with the case of constant cooling temperature. Sivasankaran and Bhuvaneswari [23] numerically analysed natural convection in a porous cavity with sinusoidal heating on both sidewalls. It is observed that the heat transfer rate is increased on increasing the amplitude ratio, porosity and Darcy number. Sivakumar and Sivasankaran [24] observed from the study on effect of non-uniform heating on mixed convection in an inclined lid-driven cavity that the average Nusselt number is extensively increased on increasing inclination angle in the buoyancy-dominated mode. Sivasankaran and Pan [25] numerically explored the natural convection of nanofluids in a cavity with sinusoidal temperature distributions on sidewalls. They concluded that the heat transfer rate is increased on increasing the amplitude ratio and volume fraction of nanoparticles.

In all of the previous studies found in the literature, mixed convection heat and mass transfers in square or rectangular enclosures are described in detail. Very few studies are performed on double-diffusive mixed convection with variation of thermal boundary condition on sidewall(s) in cavities. Non-uniform heating is very important in some applications, like solar heating, electronic equipment cooling, etc. Hence, the effect of nonuniform heating is very important in engineering applications. To the best of authors' knowledge, the problem of double-diffusive mixed convection in a lid-driven cavity with non-uniform heating on both vertical walls has not been reported so far. Keeping this in mind, the present study is concentrated on double-diffusive mixed convection in a lid-driven square cavity with sinusoidal temperature on both sidewalls.

\section{Mathematical formulation}

The physical model of a two-dimensional square cavity with size $L$ considered in this problem is illustrated in figure 1 . Sinusoidal temperatures are imposed on the vertical sidewalls of the cavity. The right wall is maintained at a higher concentration $c_{h}$ whereas the left wall is kept at a lower concentration $c_{l}$, with $c_{h}>c_{l}$. The top and bottom walls are adiabatic and impermeable to mass transfer. The top wall of the cavity is allowed to move in its own plane at a constant velocity $U_{0}$. The cavity is filled with the working fluid air. The flow is considered as unsteady, laminar and incompressible. It is further assumed that viscous dissipation is negligible in the study. The thermo-physical properties of the fluid are presumed to be constant, except the density, which varies linearly with temperature and concentration as $\rho=\rho_{0}\left[1-\beta_{T}\left(\theta-\theta_{0}\right)-\beta_{c}\left(c-c_{0}\right]\right.$, where subscript 0 denotes the reference state. Based on these assumptions, the governing equations for the conservation of mass, momentum, energy and concentration in a two-dimensional Cartesian coordinate system are as follows: 


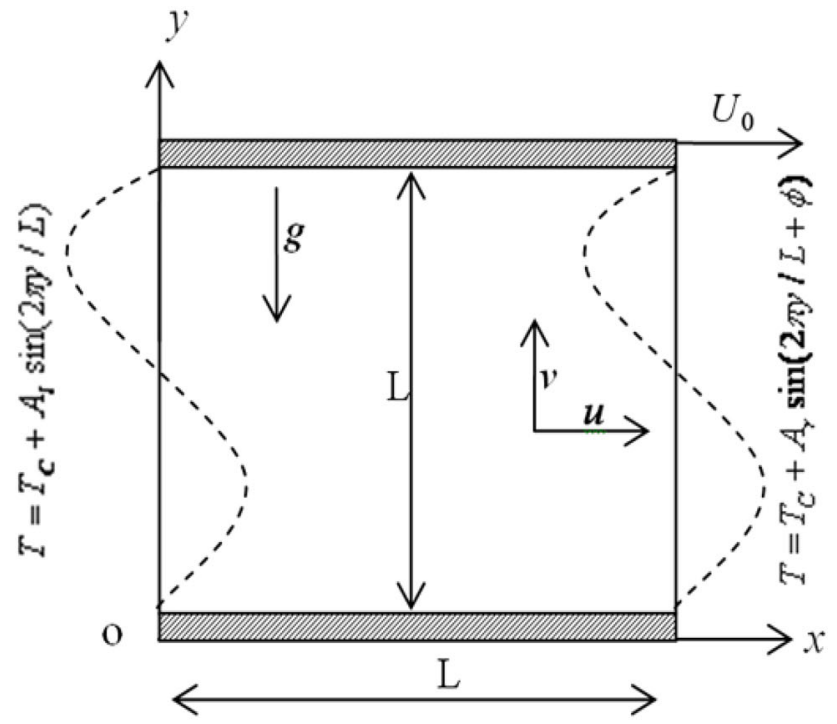

(a)

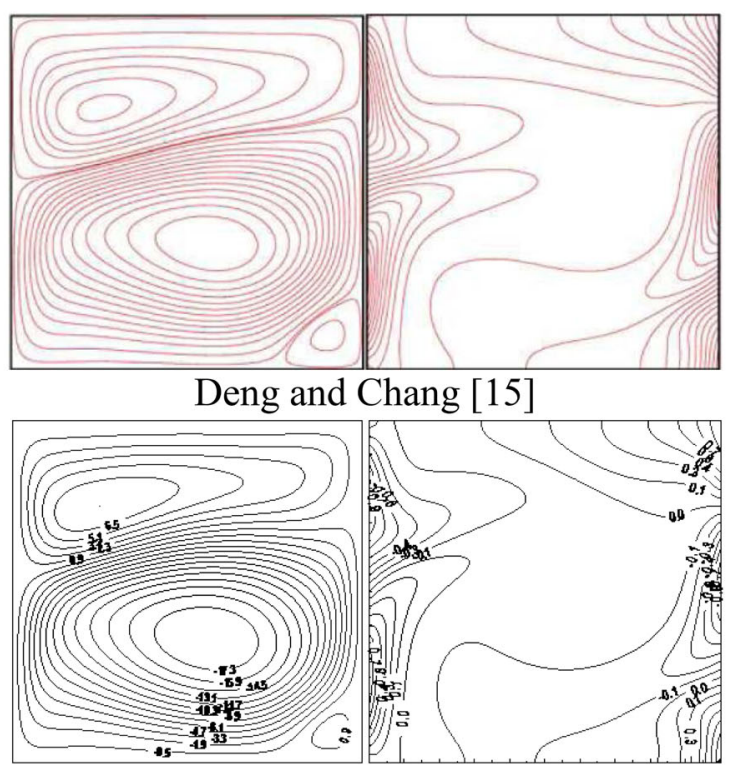

Present study

(b)

Figure 1. (a) Schematic diagram of physical configuration and coordinate system. (b) Comparison of the present results for $R a=$ $10^{5}, \varepsilon=1$ and $\varphi=\pi / 2$.

$$
\begin{gathered}
\frac{\partial u}{\partial x}+\frac{\partial v}{\partial y}=0 \\
\frac{\partial u}{\partial t}+u \frac{\partial u}{\partial x}+v \frac{\partial u}{\partial y}=-\frac{1}{\rho} \frac{\partial p}{\partial x}+v\left(\frac{\partial^{2} u}{\partial x^{2}}+\frac{\partial^{2} u}{\partial y^{2}}\right) \\
\frac{\partial v}{\partial t}+u \frac{\partial v}{\partial x}+v \frac{\partial v}{\partial y}=-\frac{1}{\rho} \frac{\partial p}{\partial y}+v\left(\frac{\partial^{2} v}{\partial x^{2}}+\frac{\partial^{2} v}{\partial y^{2}}\right) \\
+g \beta_{T}\left(T-T_{C}\right)+g \beta_{c}\left(c-c_{l}\right)
\end{gathered}
$$

$$
\begin{gathered}
\frac{\partial T}{\partial t}+u \frac{\partial T}{\partial x}+v \frac{\partial T}{\partial y}=\alpha\left(\frac{\partial^{2} T}{\partial x^{2}}+\frac{\partial^{2} T}{\partial y^{2}}\right) \\
\frac{\partial c}{\partial t}+u \frac{\partial c}{\partial x}+v \frac{\partial c}{\partial y}=D\left(\frac{\partial^{2} c}{\partial x^{2}}+\frac{\partial^{2} c}{\partial y^{2}}\right)
\end{gathered}
$$

The initial and boundary conditions for the considered problem can be written as follows:

Initial condition $(t=0)$ :

$$
\begin{aligned}
& u=0, \quad v=0, \quad T=T_{c}, \quad c=c_{l}, \quad 0 \leq x \leq L \\
& 0 \leq y \leq L .
\end{aligned}
$$

Boundary conditions $(t>0)$ :

$$
\begin{aligned}
& u=0, \quad v=0 ; \quad \frac{\partial T}{\partial y}=0, \quad \frac{\partial c}{\partial y}=0, \quad y=0 \\
& u=U_{0}, \quad v=0 ; \quad \frac{\partial T}{\partial y}=0, \quad \frac{\partial c}{\partial y}=0, \quad y=L \\
& u=v=0 ; \quad T=T_{l}(y)=T_{c}+A_{l} \sin \left(\frac{2 \pi y}{L}\right) \\
& c=c_{l}, \quad x=0 \\
& u=v=0 ; \quad T=T_{r}(y)=T_{c}+A_{r} \sin \left(\frac{2 \pi y}{L}+\phi\right) \\
& c=c_{h}, \quad x=L
\end{aligned}
$$

where the reference/mean temperatures of the sinusoidal temperature profiles on the left and right sidewalls are taken as the same, i.e., $T_{c}$. The amplitude and phase deviation of the sinusoidal profiles are $A_{l}$ and 0 for left sidewall and $A_{r}$ and $\varphi$ for right sidewall, respectively.

To write the dimensional equations (1)-(5) in a proper non-dimensional form, the following dimensionless variables are used:

$$
\begin{gathered}
X=\frac{x}{L}, \quad Y=\frac{y}{L}, \quad U=\frac{u}{U_{0}}, \quad V=\frac{v}{U_{0}}, \quad \theta=\frac{T-T_{c}}{\Delta t}, \\
\tau=\frac{t U_{0}}{L}, \quad \zeta=\omega L / U_{0}, \quad \Psi=\psi / L U_{0} \quad \text { and } \\
C=\frac{c-c_{l}}{c_{h}-c_{l}} .
\end{gathered}
$$

After non-dimensionalization, these governing equations can be rewritten in the vorticity-stream function formulation as follows:

$$
\begin{gathered}
\frac{\partial \zeta}{\partial \tau}+U \frac{\partial \zeta}{\partial X}+V \frac{\partial \zeta}{\partial Y}=\frac{1}{R e}\left(\frac{\partial^{2} \zeta}{\partial X^{2}}+\frac{\partial^{2} \zeta}{\partial Y^{2}}\right) \\
+R i\left(\frac{\partial \theta}{\partial X}+N \frac{\partial C}{\partial X}\right) \\
\frac{\partial^{2} \Psi}{\partial X^{2}}+\frac{\partial^{2} \Psi}{\partial Y^{2}}=-\zeta
\end{gathered}
$$




$$
\begin{array}{r}
\frac{\partial \theta}{\partial \tau}+U \frac{\partial \theta}{\partial X}+V \frac{\partial \theta}{\partial Y}=\frac{1}{\operatorname{PrRe}\left(\frac{\partial^{2} \theta}{\partial X^{2}}+\frac{\partial^{2} \theta}{\partial Y^{2}}\right)} \\
\frac{\partial C}{\partial \tau}+U \frac{\partial C}{\partial X}+V \frac{\partial C}{\partial Y}=\frac{1}{S c R e}\left(\frac{\partial^{2} C}{\partial X^{2}}+\frac{\partial^{2} C}{\partial Y^{2}}\right)
\end{array}
$$

where

$$
U=\frac{\partial \Psi}{\partial Y}, \quad V=-\frac{\partial \Psi}{\partial X} \quad \text { and } \quad \zeta=\frac{\partial V}{\partial X}-\frac{\partial U}{\partial Y} .
$$

The dimensionless parameters in these equations are defined as follows: $G r_{T}=\left(g \beta_{T}\left(\theta_{h}-\theta_{c}\right) L^{3}\right) / v^{2}$ is the thermal Grashof number, $G r_{C}=\left(g \beta_{c}\left(c_{h}-c_{l}\right) L^{3}\right) / v^{2}$ is the solutal Grashof number, $N=\frac{\beta_{c}\left(c_{h}-c_{l}\right)}{\beta_{T}\left(\theta_{h}-\theta_{c}\right)}=\frac{G r_{C}}{G r_{T}}$ is the buoyancy ratio, $\operatorname{Pr}=v / \alpha$ is the Prandtl number, $R e=U_{0} L / v$ is the Reynolds number, $R i=\frac{G r_{T}}{R e^{2}}$ is the Richardson number and $S c=\frac{v}{D}$ is the Schmidt number. The dimensionless initial and boundary conditions of the present problem can be written as follows.

$$
\begin{array}{lllll}
\text { For } \tau=0: & U=0 ; & V=0, & \theta=0, \quad C=0 & 0 \leq X \leq 1, \quad 0 \leq Y \leq 1 . \\
\text { For } \tau>0: & U=0 ; & V=0, \quad \frac{\partial \theta}{\partial Y}=\frac{\partial C}{\partial Y}=0, & Y=0 \\
& U=1 ; & V=0, \quad \frac{\partial \theta}{\partial Y}=\frac{\partial C}{\partial Y}=0, & Y=1 \\
& U=0 ; & V=0, \quad \theta=\sin (2 \pi Y), & C=0, \quad X=0 \\
U=0 ; & V=0, \quad \theta=\varepsilon \sin (2 \pi Y+\varphi), & C=1, \quad X=1
\end{array}
$$

where $\varepsilon=A_{r} / A_{l}$ is the amplitude ratio of the sinusoidal temperature on right sidewall to that on left wall of the cavity.

In thermal engineering applications, it is obvious that the most essential physical quantities in the study are heat and mass transfer rates, which are calculated by the Nusselt number and Sherwood number, respectively. The local Nusselt numbers on the left and right sidewalls of the cavity are defined as $N u_{l}=-\left(\frac{\partial \theta}{\partial X}\right)_{X=0}$ and $N u_{r}=-\left(\frac{\partial \theta}{\partial X}\right)_{X=1}$, respectively. The total heat transfer rate across the cavity is the sum of the averaged Nusselt numbers along the heating halves of both vertical sidewalls. The total heat transfer rate across the enclosure along the heating halves of both vertical sidewalls are calculated as $\quad \overline{N u}=\int_{\text {heating half }}$ $N u_{l} d Y+\int_{\text {heating half }} N u_{r} d Y$. The local Sherwood number and average Sherwood number at the right wall of the cavity are expressed as $S h=-\left(\frac{\partial C}{\partial X}\right)_{X=1}$ and $\overline{S h}=$ $\int_{0}^{1} S h d Y$, respectively.

\section{Method of solution}

The non-dimensional equations (8)-(12) are discretized using the finite-volume method. The upwind differencing scheme and the central difference scheme are implemented for the non-linear convection and the diffusion terms, respectively. The central difference approximation is applied to evaluate the velocity components $U$ and $V$ at every grid point in the cavity. The resulting sets of algebraic equations are solved by an iterative process. The trapezoidal rule is used to compute the average Nusselt and Sherwood numbers along the vertical wall. This process is repeated until the following convergence criterion for temperature, concentration, vorticity and stream function is satisfied: $\left|\frac{\Phi_{n+1}(i, j)-\Phi_{n}(i, j)}{\Phi_{n+1}(i, j)}\right|<10^{-6}$ where $n$ denotes the previous calculation in iteration and $n+1$ denotes the current iteration and $\Phi$ represents the field variable $(\theta, C, \zeta$ or $\Psi)$. A uniform grid is taken in both $x$ and $y$ directions to compute the numerical solutions of the considered problem. The grid size is varied from $41 \times 41$ to $161 \times 161$ to find the grid-independent solutions with $R i=1, P r=0.71$ and $N=0$. The grid-independence test showed that a grid of $81 \times 81$ size is enough to obtain the desired accuracy of results. The results are compared and tabulated in table 1 . It shows that the results obtained are seen to be in good agreement with the existing solutions.

\section{Results and discussion}

A numerical study has been carried out on double-diffusive mixed convective flow in a lid-driven square cavity with sinusoidal boundary temperatures and different concentrations at the left and right sidewalls. In the present investigation, the Prandtl number $P r=0.71$ pertaining to air is fixed. The numerical computations are carried out by varying the controlling parameters such as the Richardson number $\left(R i=G r_{T} / R e^{2}\right)$, the phase deviation $(\varphi)$ and the amplitude ratio $(\varepsilon)$. The virtual importance of solutal over thermal buoyancy forces is denoted by the buoyancy ratio $(N)$, and is defined as the ratio of the solutal buoyancy force

\begin{tabular}{|c|c|c|c|c|c|c|}
\hline \multirow[b]{3}{*}{$G r$} & \multicolumn{6}{|c|}{$\overline{N u}$} \\
\hline & \multicolumn{3}{|c|}{$\operatorname{Re}=400$} & \multicolumn{3}{|c|}{$\operatorname{Re}=1000$} \\
\hline & $\begin{array}{c}\text { Present } \\
\text { work }\end{array}$ & $\begin{array}{c}\text { Sharif } \\
\text { [26] }\end{array}$ & $\begin{array}{l}\text { Iwatsu } \\
\text { et al [27] }\end{array}$ & $\begin{array}{c}\text { Present } \\
\text { work }\end{array}$ & $\begin{array}{c}\text { Sharif } \\
\text { [26] }\end{array}$ & $\begin{array}{l}\text { Iwatsu } \\
\text { et al [27] }\end{array}$ \\
\hline $10^{2}$ & 4.08 & 4.05 & 3.84 & 6.48 & 6.55 & 6.33 \\
\hline $10^{4}$ & 3.84 & 3.82 & 3.62 & 6.47 & 6.50 & 6.29 \\
\hline $10^{6}$ & 1.10 & 1.17 & 1.22 & 1.66 & 1.81 & 1.77 \\
\hline
\end{tabular}
to thermal buoyancy force. The range for the buoyancy ratio is set from $N=-5$ to $N=5$, covering the concentration-dominated opposing flow $(N=-5)$, pure thermal convection dominated flow $(N=0)$ and concentrationdominated aiding flow $(N=5)$. The Grashof number $(G r)$

Table 1. Comparison of average Nusselt number with available results in the literature for lid-driven cavity. 
is varied from $10^{2}$ to $10^{6}$ and the values of Reynolds number $R e=100$ and Schmidt number $S c=5$ are fixed. The different values of Richardson number $(R i)$ are $0.01,1$ and 100 . The phase deviation takes the values $\phi=0, \pi / 4, \pi / 2,3 \pi / 4$ and $\pi$. The amplitude ratio assumes the values such as $\varepsilon=0,0.25,0.5$ and 1 . From the obtained results, the effects of compositional buoyancy force and shear force on heat and mass transfer characteristics and fluid flow field have been examined.

\subsection{Effects of buoyancy ratio}

Figure $2 \mathrm{a}-\mathrm{c}$ shows the effects of different values of buoyancy ratio on fluid flow when Richardson number is fixed constant at $R i=1$. Flow of fluid appears as a single major cell occupying the whole cavity at $N=-5$ for $\varepsilon=0$ and $\varphi=0$ in figure 2a. The change of the buoyancy ratio from -5 to 0 causes a little variation in the fluid flow. Flow speed slightly increases and the fluid in right-bottom corner of the cavity becomes stagnant. On increasing the buoyancy ratio to 5 , significant changes are observed in flow field inside the cavity. The single major cell splits into two cells. One large cell is elongated in the lower part of the cavity and another cell gets closer to the moving wall. When amplitude ratio is increased to $\varepsilon=1$ with phase deviation $\phi=0$, from figure $2 \mathrm{~b}$, it can be viewed that flow pattern is similar to the previous case for all values of buoyancy ratio. In figure $2 \mathrm{c}$, when the amplitude ratio and phase deviation are, respectively, 1 and $\pi$, the core region of the single cell is very close to the top right corner of the cavity at $N=-5$ and 0 . Further, the circulation of the fluid slightly increases. The single cell is elongated and gets broken into two cells at $N=5$. It is clear that the streamlines are affected by concentration-dominated aiding flow at $N=5$ for all the values of amplitude ratio and phase deviation at the mixed convection regime.

The temperature distributions for various values of buoyancy ratio with $\varepsilon=0$ and 1 and $\phi=0$ and $\pi$ are depicted in figure $3 \mathrm{a}-\mathrm{c}$. In figure $3 \mathrm{a}$, non-uniform heating is imposed only on the left sidewall whereas temperature distribution of the right wall is kept constant. The heat transfer characteristics are affected along the left sidewall of the enclosure for all the values of buoyancy ratio when $\varepsilon=0$ and $\phi=0$. On increasing the amplitude ratio to $\varepsilon=$ 1 , non-uniform heating is enforced also on the right sidewall of the cavity, which is shown in figure $3 \mathrm{~b}$. The heat transfer is enhanced near both sidewalls and inside the cavity for all the values of $N$. Thermal boundary layers are formed along both sidewalls. A significant heat distribution is observed throughout the cavity from figure $3 \mathrm{c}$ for $\varepsilon=1$ and $\phi=\pi$. The isotherms in figure 3 show that the heat distribution is increased on increasing the buoyancy ratio from $N=-5$ to 5 when the amplitude ratio and phase deviation are, respectively, 1 and $\pi$.
The concentration gradients at various values of $N, \varepsilon$ and $\varphi$ are depicted in figure $4 \mathrm{a}-\mathrm{c}$. The solutal boundary layers in either side of the cavity reveal that mass distribution is enhanced more remarkably along the left and right sidewalls than in the middle of the cavity. Similar contours of concentration are observed for all values of $\varepsilon$ and $\varphi$, which are shown in figure $4 \mathrm{a}-\mathrm{c}$ for concentration-dominated opposing flow $(N=-5)$. For $N=0$, a small elliptical cell is formed in the middle of the cavity when the amplitude ratio and phase deviation are zero. Due to the amplitude ratio change, the small elliptical cell tends to deform inside the cavity. The concentration lines seem to spread throughout the cavity in the regime of the concentrationdominated aiding flow $(N=5)$ in figure $4 \mathrm{~b}$. Further, though the phase deviation is increased to $\phi=\pi$, from figure $4 c$, it can be noted that no significant difference in the concentration contours is observed for $N=-5$ and $N=0$. The mass distribution is boosted up appreciably within the cavity for the concentration-dominated aiding flow regardless of the values of $\varepsilon$ and $\varphi$. In general, mass distribution becomes noteworthy in the regime of concentration-dominated aiding flow for all the values of amplitude ratio and phase deviation at $R i=1$.

\subsection{Effects of Richardson number}

The effect of Richardson numbers on streamlines, isotherms and concentrations for different values of $\varepsilon$ and $\phi$ with $N=5$ is discussed in figure $5 \mathrm{a}-\mathrm{c}$. In figure $5 \mathrm{a}$, a single major circulating cell is formed due to the shear force by the movement of the top wall for $R i=0.01$. The core region of the cell is near the upper part of the cavity. On increasing the Richardson number to 100 , the flow field is totally distorted and occupies the whole cavity. The circulating cell elongates and tends to break. Further, the core region appears near the left sidewall of the cavity. For $R i=0.01$, the isotherms are distributed only in left half of the enclosure. Meanwhile, a thermal boundary layer occurs with sharp gradients on the left sidewall for $R i=100$. At $R i=0.01$, the concentration contours on the left and right sidewalls show that mass distribution occurs only near the vertical walls. However, in the natural convection regime, the concentration shows horizontal solutal stratification inside the cavity. Moreover, a strong solutal boundary layer is formed on the left and right sidewalls. The streamlines and concentrations in the forced convection mode are similar to those in figure 5a though the amplitude ratio is increased to $\varepsilon=1$. This can be viewed in figure $5 \mathrm{~b}$. Since $\varepsilon=1$, temperature on the right wall is also kept sinusoidal. Hence, both walls have identical temperature distribution. When $R i=100$, the streamlines are elongated diagonally and two secondary cells appear with their core region in the cavity. Strong thermal and solutal boundary layers are formed along the left and right sidewalls in the natural convection regime. On increasing phase 

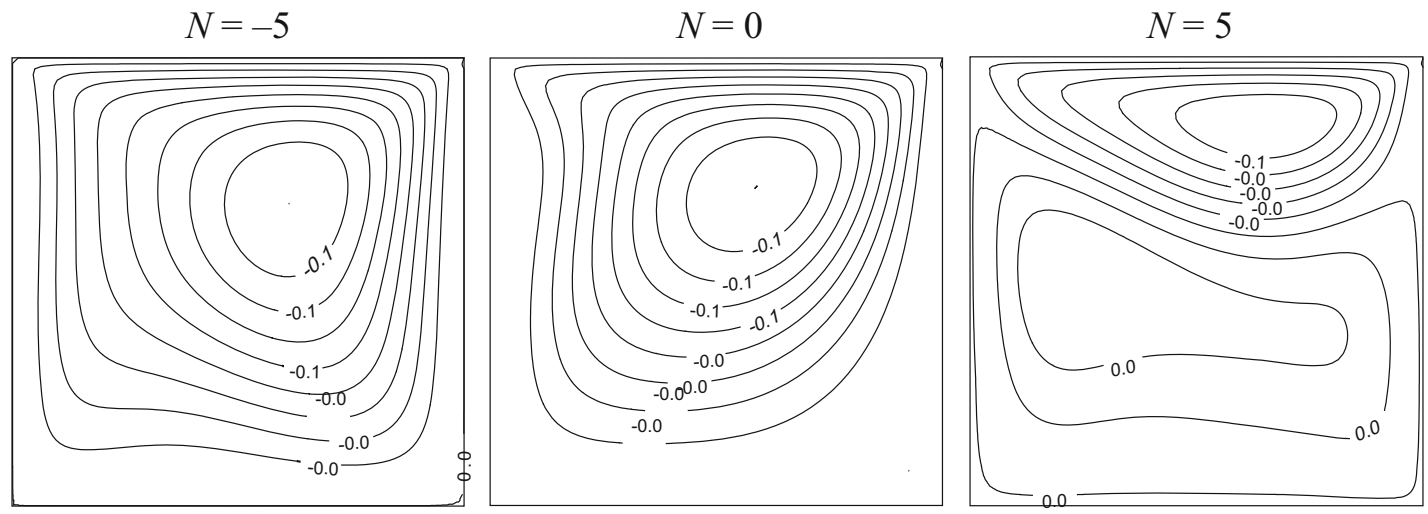

(a)
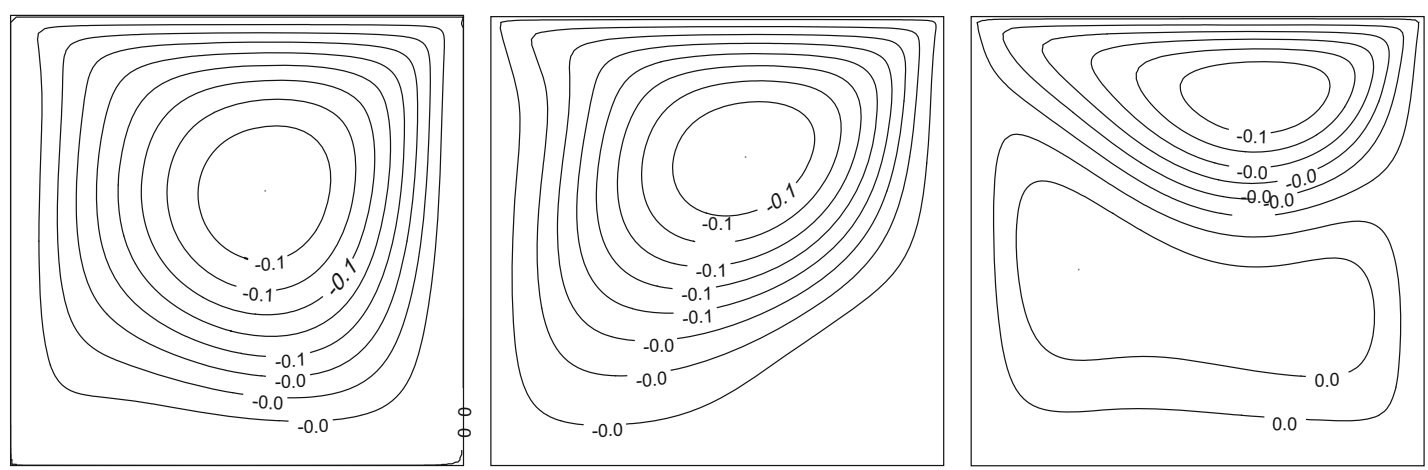

(b)
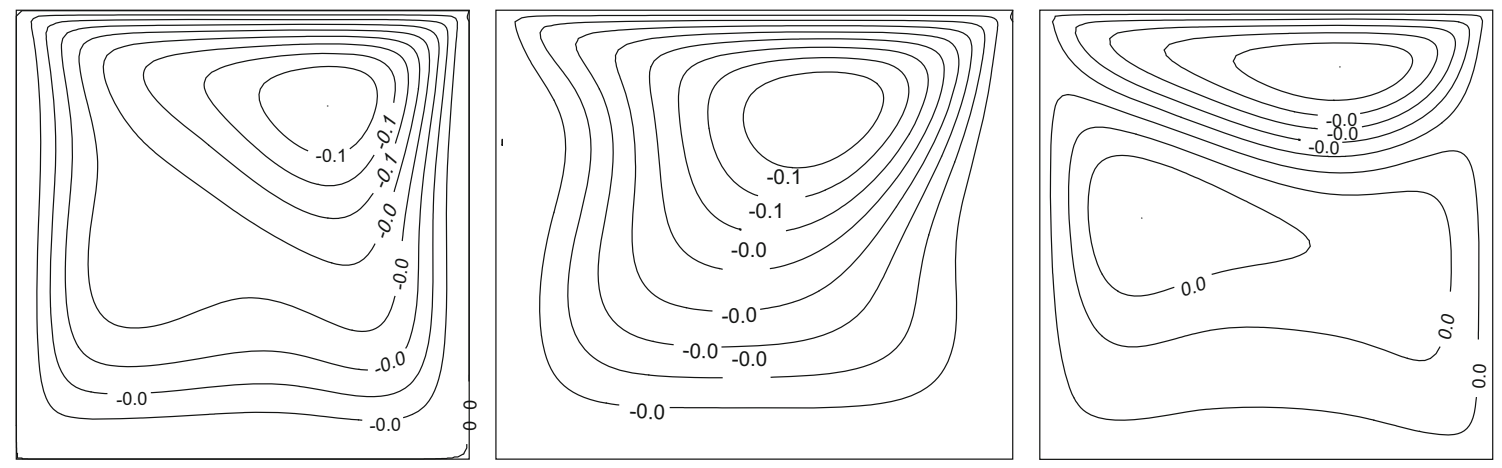

(c)

Figure 2. Streamlines for different values of buoyancy ratio, $\varepsilon$ and $\varphi$ with $R i=1$. (a) $\varepsilon=0, \varphi=0$. (b) $\varepsilon=1, \varphi=0$. (c) $\varepsilon=1, \varphi=\pi$.

deviation to $\phi=\pi$ (see figure $5 \mathrm{c}$ ), a single major circulating cell appears for $R i=0.01$ and slightly moves towards the top wall due to the shear force. In natural convection mode, it is interesting to see that cell elongates horizontally with two inner cells and occupying the cavity. The temperature and concentration contour lines are affected in the forced convection regime when $\phi=\pi$. In the case of free convection mode, the isotherms and concentrations boundary layers are formed with sharp gradients on the vertical walls. Obviously, it can be noted from figure $5 \mathrm{a}-\mathrm{c}$ that streamlines, isotherms and concentration lines are strongly affected in the free convection mode than in forced convection mode.

The average Nusselt number versus the buoyancy ratio is displayed in figure $6 \mathrm{a}$ and $\mathrm{b}$ for $\varepsilon=0, \phi=0$ and $\varepsilon=1$, $\phi=0$ respectively. On increasing Richardson number from $R i=0.01$ to $R i=100$, the overall heat transfer rate gradually increases for $\varepsilon=0$ and $\phi=0$. Meanwhile, the average heat transfer rate decreases when $\varepsilon=1$ and $\phi=0$. Keeping $N=1$ and $\phi=0$ constant, the variation of 
$N=-5$
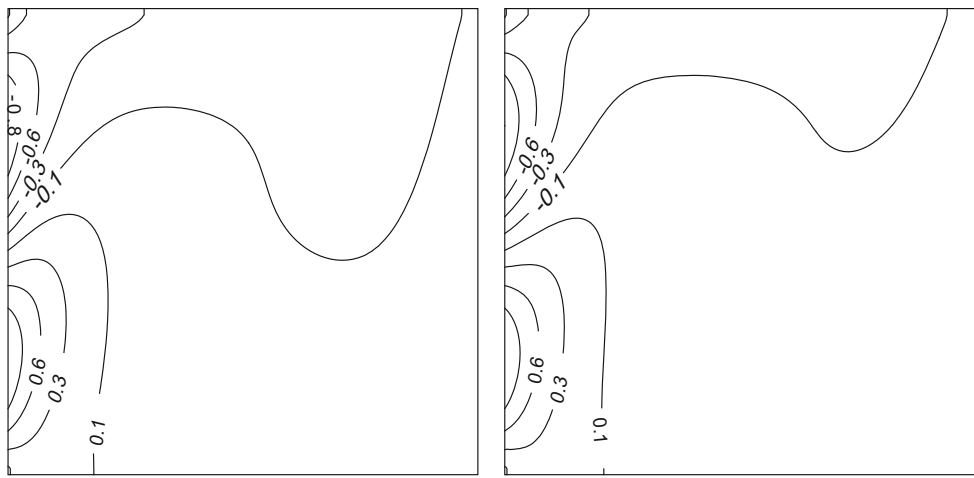

(a)
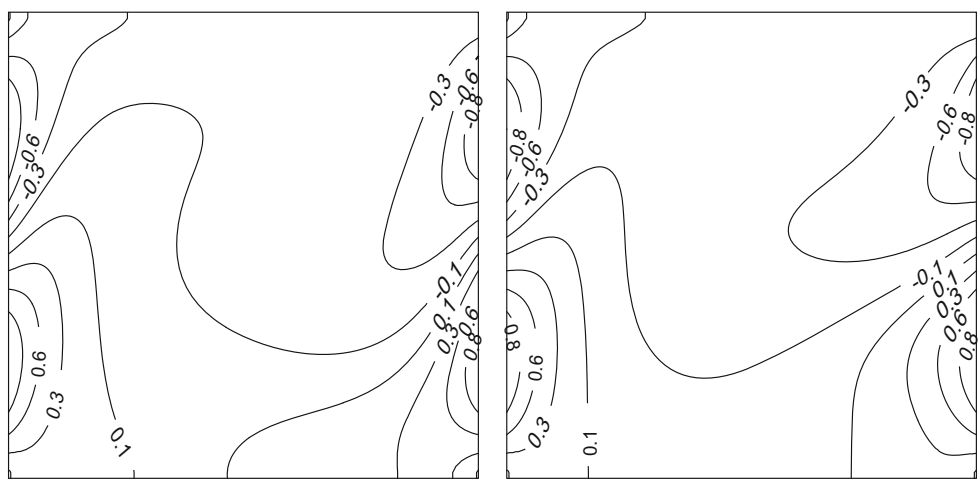

(b)
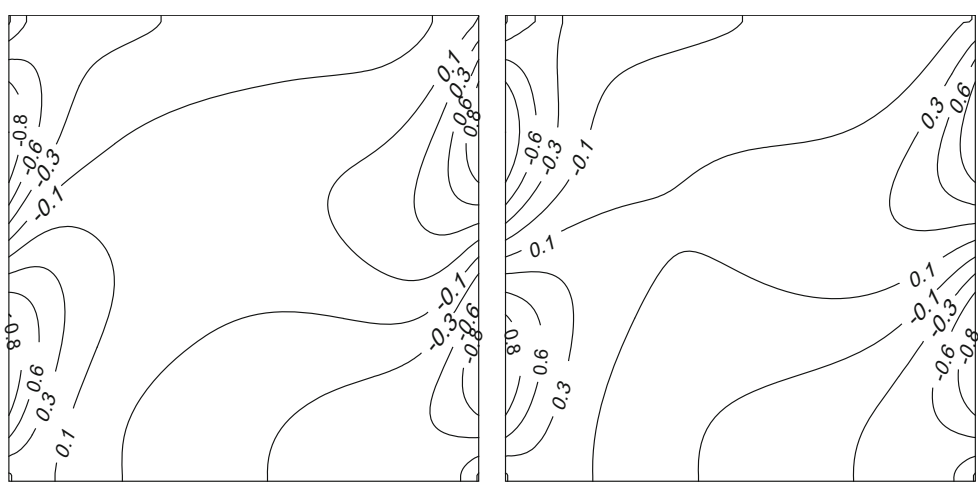

(c)

.

$N=5$
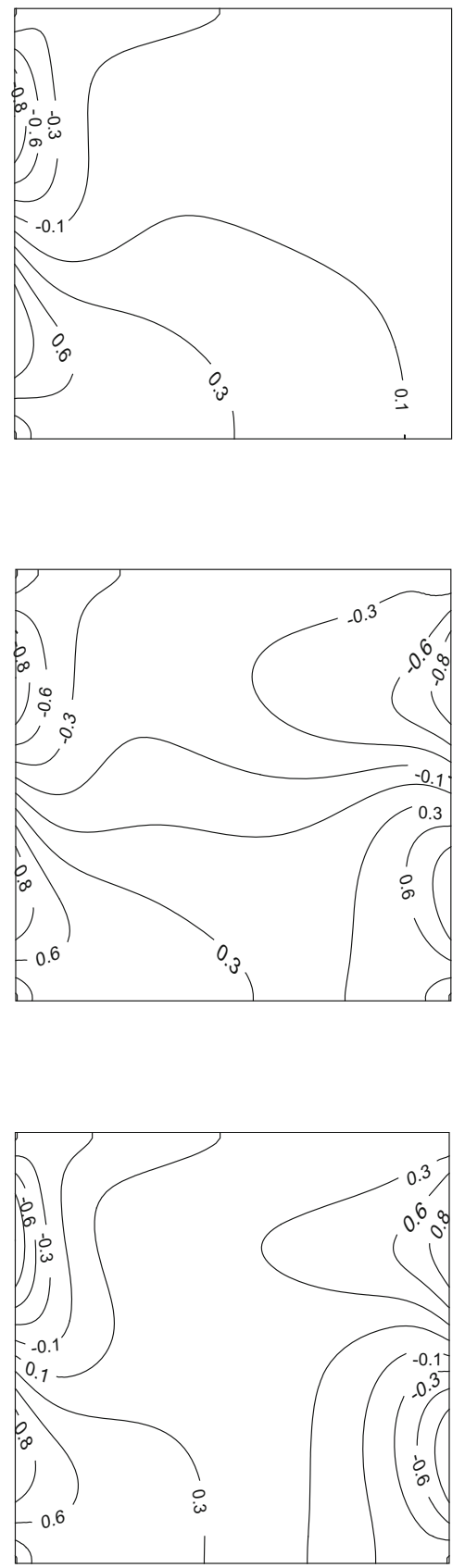

Figure 3. Isotherms for different values of buoyancy ratio, $\varepsilon$ and $\varphi$ with $R i=1$. (a) $\varepsilon=0, \varphi=0$. (b) $\varepsilon=1, \varphi=0$. (c) $\varepsilon=1, \varphi=\pi$.

average Nusselt number is plotted against the Richardson numbers in figure 6c. It is obviously seen that the average Nusselt number is increased when the amplitude ratio increases from $\varepsilon=0$ to $\varepsilon=1$. Moreover, it can be noticed that the increase starts in the regime of natural convection. The overall heat transfer rate increases for the first three phase deviation values $\phi=0, \pi / 4, \pi / 2$; thereafter, it decreases for $\phi=3 \pi / 4$ and $\pi$, which is shown in figure $6 \mathrm{~d}$ for $N=1$ and $\varepsilon=1$. In addition, average heat transfer rate is higher for the phase value $\phi=3 \pi / 4$ in the buoyancydriven convection and the heat transfer rate is lower in forced and mixed convection regime for $\phi=0$.

The average Sherwood number is plotted in figure 7ad against the buoyancy ratio for different Richardson 
$N=-5$
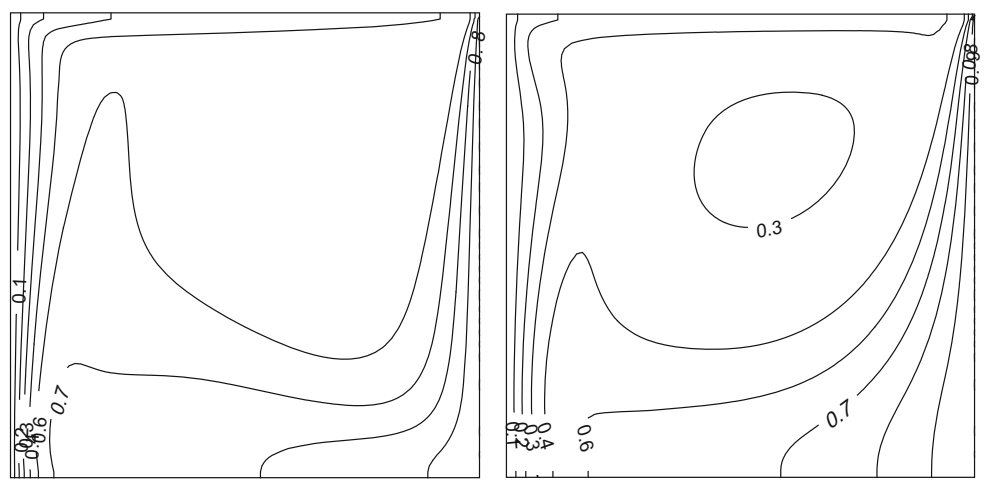

(a)
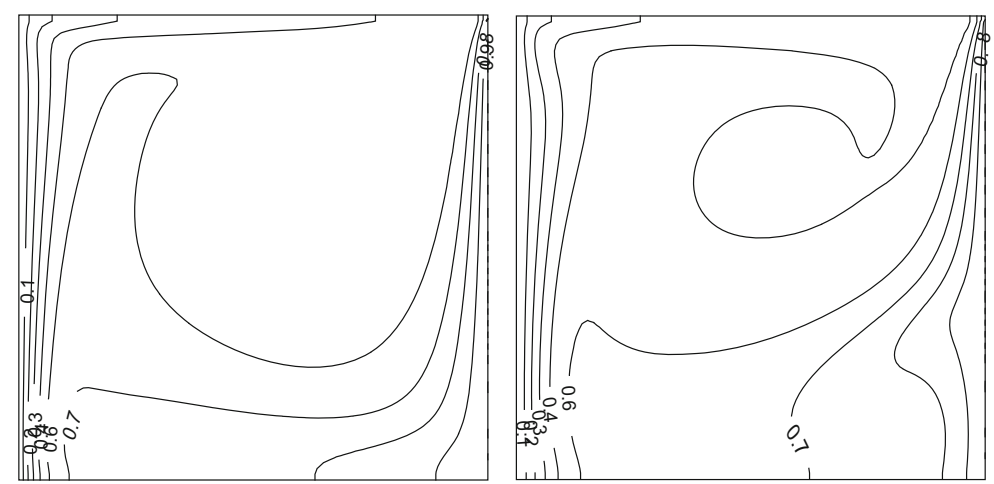

(b)
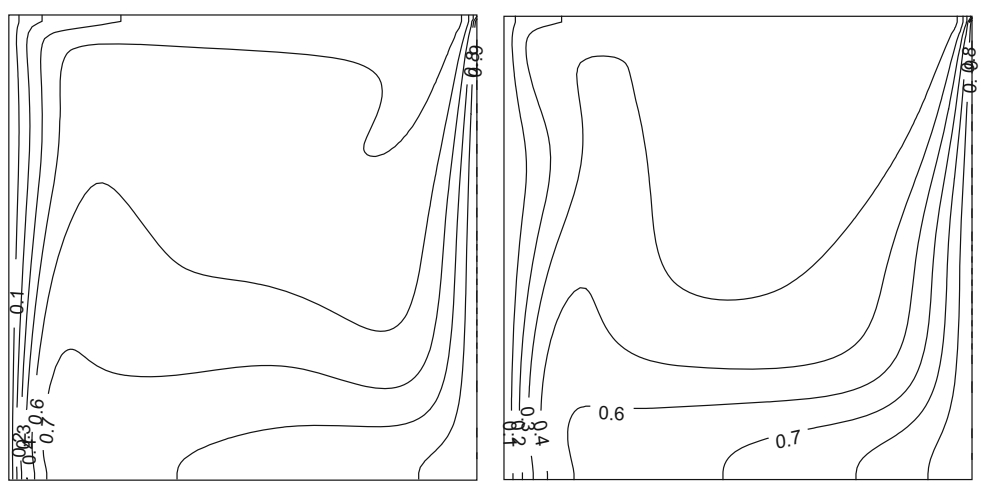

(c)
$N=5$
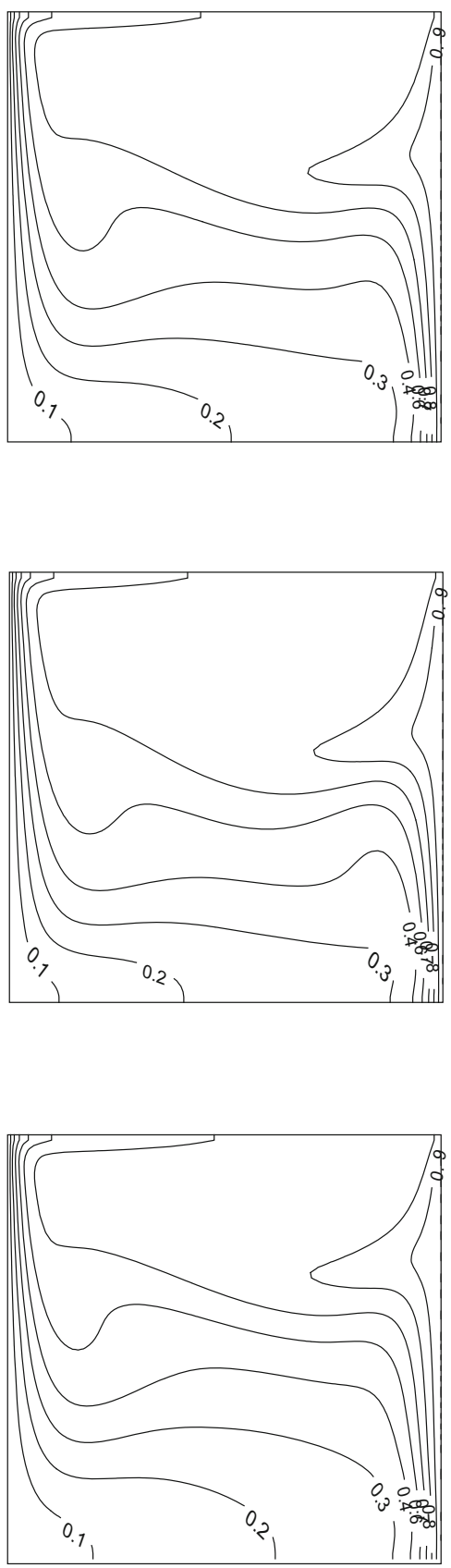

Figure 4. Concentrations for different values of buoyancy ratio, $\varepsilon$ and $\varphi$ with $R i=1$. (a) $\varepsilon=0, \varphi=0$. (b) $\varepsilon=1, \varphi=0$. (c) $\varepsilon=1, \varphi=\pi$.

numbers, $\varepsilon$ and $\phi$. The overall mass transfer rate decreases for $R i=0.01$ and $R i=0.1$ but it increases for $R i=1-100$ when amplitude ratio and phase deviation are zero, which is exhibited in figure $7 \mathrm{a}$. The variation of mass transfer rate is precisely the same as in the previous case even for $\varepsilon=1$ when $\phi=0$. This is depicted in figure $7 \mathrm{~b}$. When $N=1$ and $\phi=0$, figure $7 \mathrm{c}$ reveals that there is no reliable trend found in the overall mass transfer rate on increasing amplitude ratio in the regimes of mixed and forced convection. Further, the average mass transfer rate increases on increasing the values of amplitude ratio in the natural convection mode. The mass transfer rate gradually decreased on increasing the amplitude ratio at $R i=0.01$, whereas it increased in the 

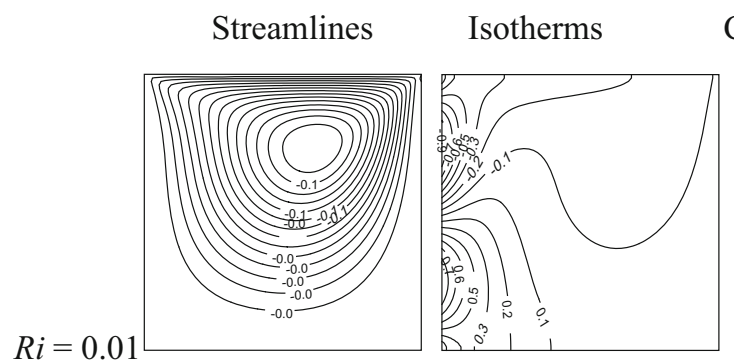

Concentrations
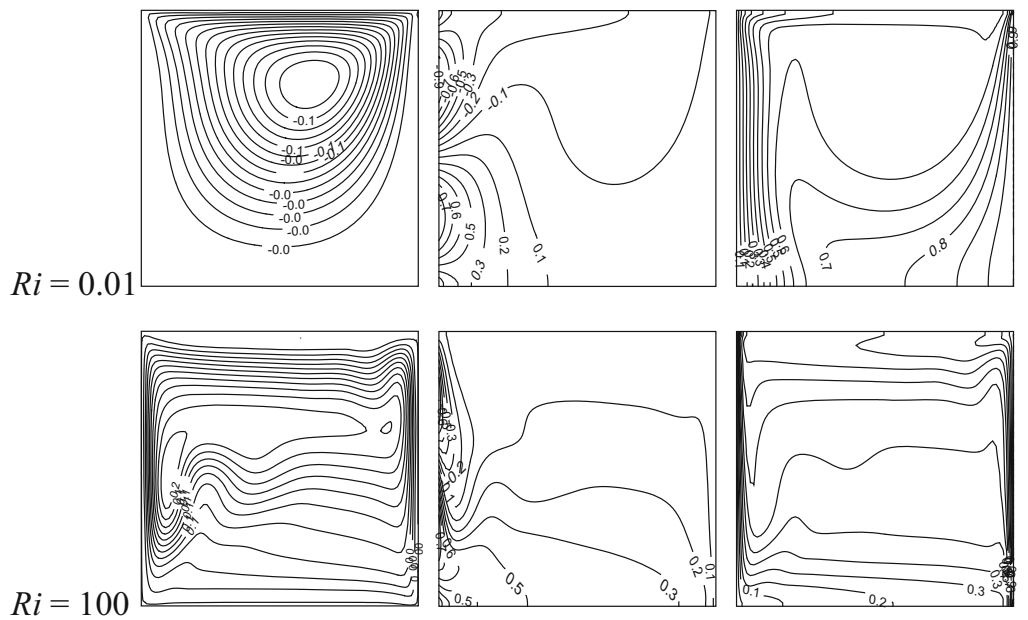

$R i=100$

(a)
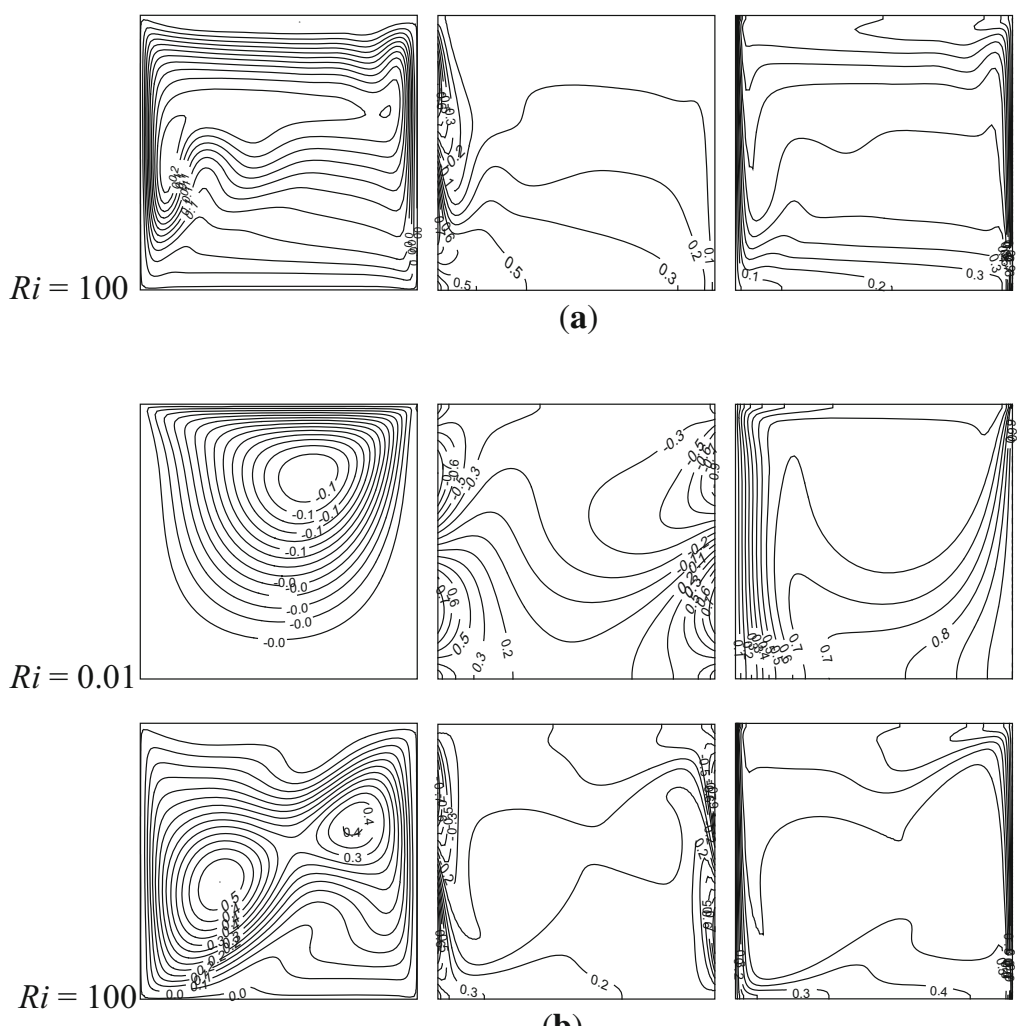

(b)
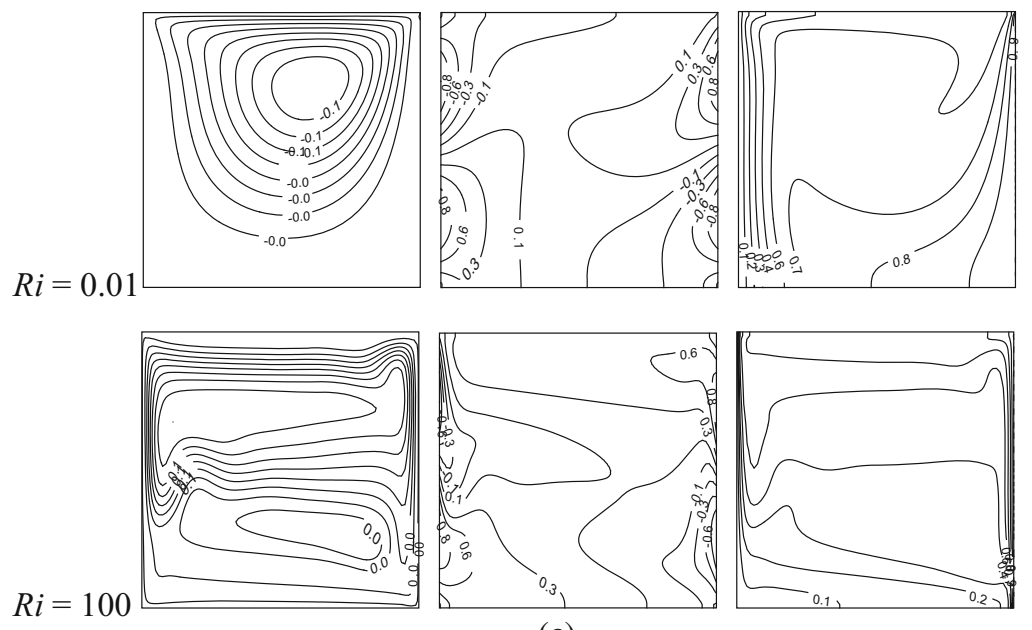

(c)

Figure 5. Streamlines, isotherms and concentrations for different values of $\varepsilon, \varphi$ and $N=5$ with $R i=0.01$ and 100 . (a) $\varepsilon=0, \varphi=0$ and $N=5$. (b) $\varepsilon=1, \varphi=0$ and $N=5$. (c) $\varepsilon=1, \varphi=\pi$ and $N=5$. 


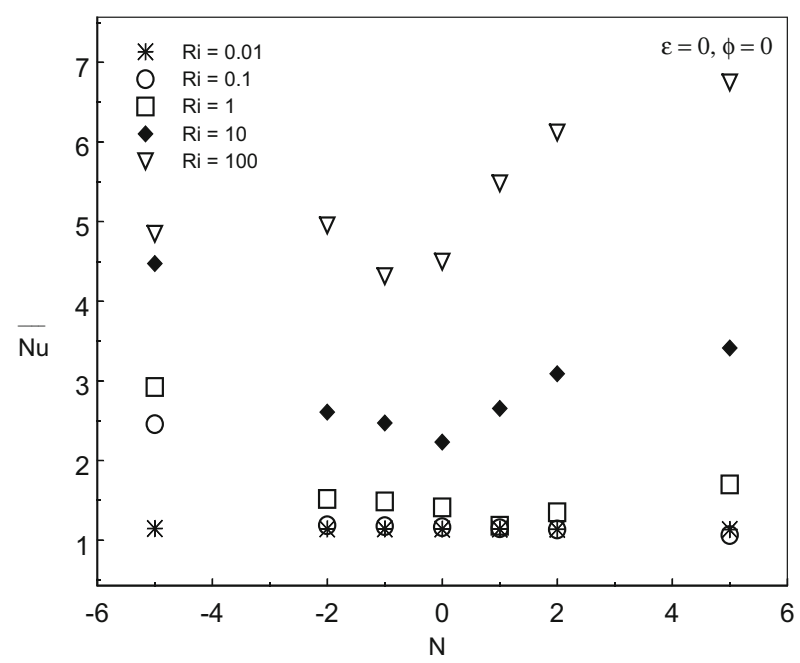

(a)

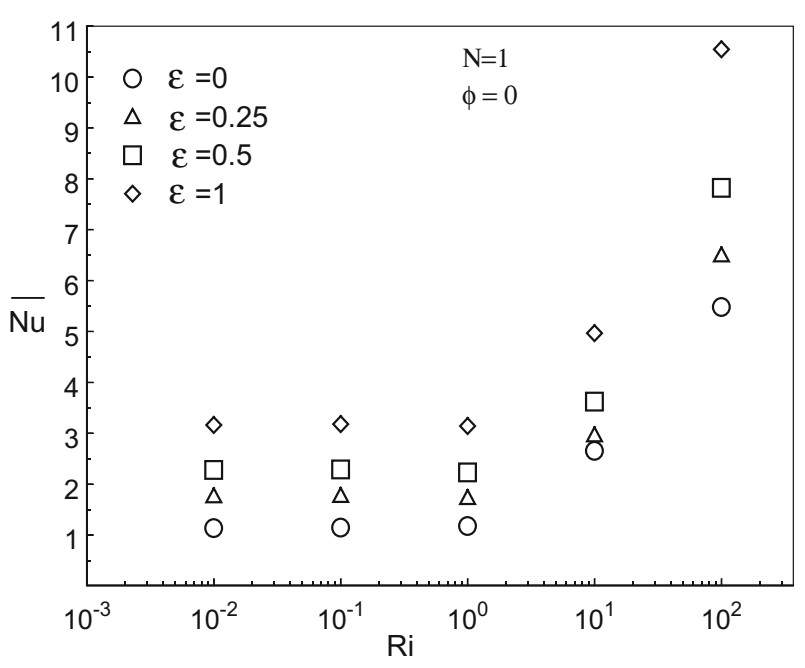

(c)

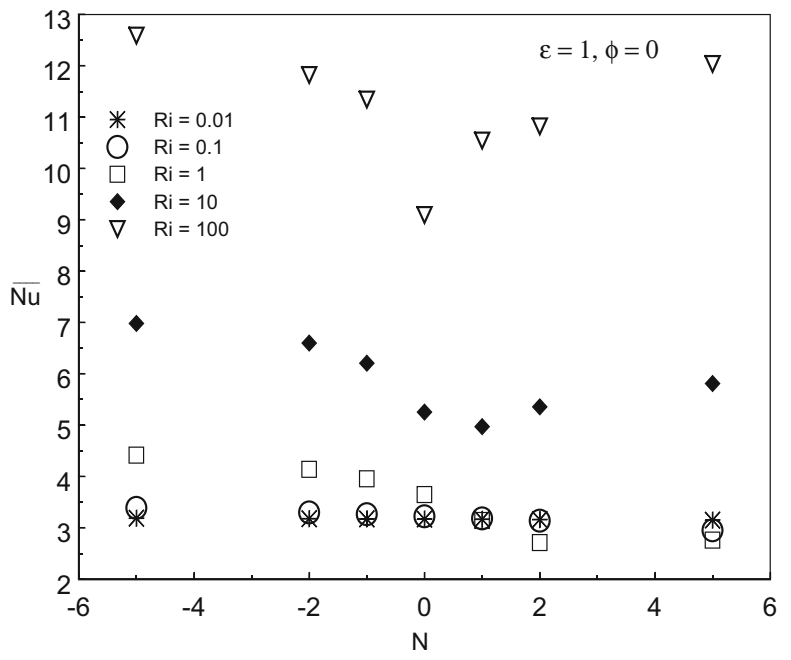

(b)

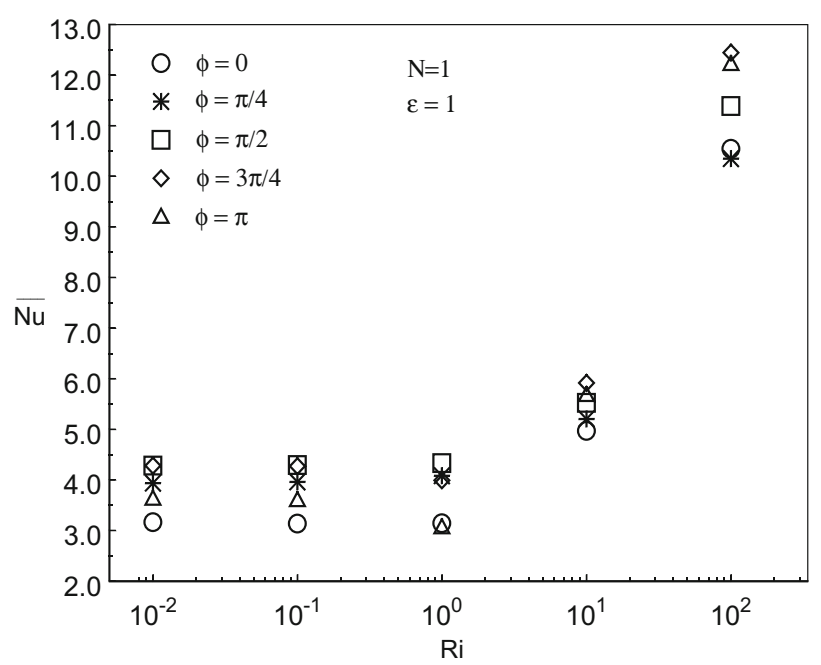

(d)

Figure 6. Average Nusselt number for different values of $N$ and $R i$ with different values of $\varepsilon$ and $\varphi$.

free convection mode when the amplitude ratio varied from 0 to 1 . The difference in the average Sherwood number for different values of $\varepsilon$ is very small in the forced convection mode. However, in the free convection mode, remarkable difference of mass transfer rate exist with increasing amplitude ratio values. The graph of average Sherwood number versus Richardson number at different values of phase deviation values for $N=1$ and $\varepsilon=1$ is viewed in figure $7 \mathrm{~d}$. Little variation in mass transfer rate is found when the phase deviation value is increased from $\phi=0$ to $\pi$ in forced and mixed convection regimes. It is observed that the mass transfer rate is increased by increasing phase deviation value in the free convection mode.

\section{Conclusion}

This paper presents a numerical study to examine the effect of double-diffusive mixed convection with sinusoidal temperature on both vertical sidewalls in a lid-driven square cavity. Sinusoidally varying temperature on the left and right sidewalls and constant mass distributions are maintained. The following results are observed.

- The heat and mass transfer rates are affected by the phase deviation and amplitude ratio for all values of Richardson number.

- Multi-cellular flow pattern is observed in the buoyancy-assisted mixed convection regime for all values of amplitude ratio and phase deviation. 


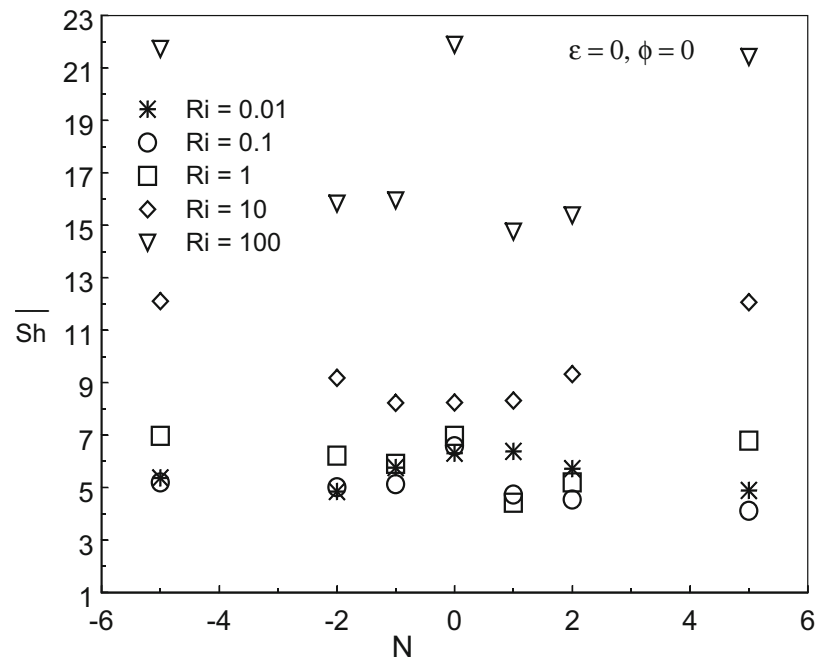

(a)

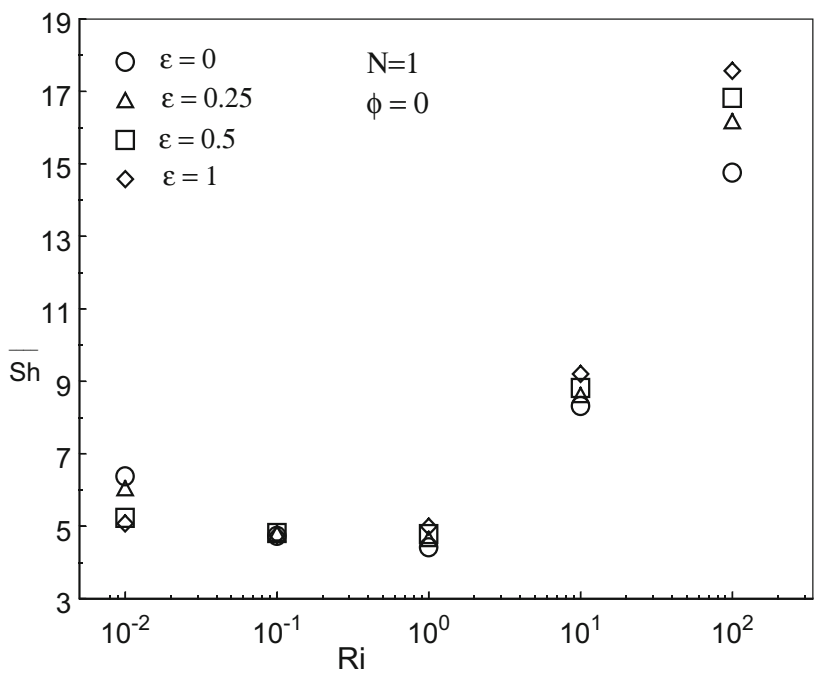

(c)

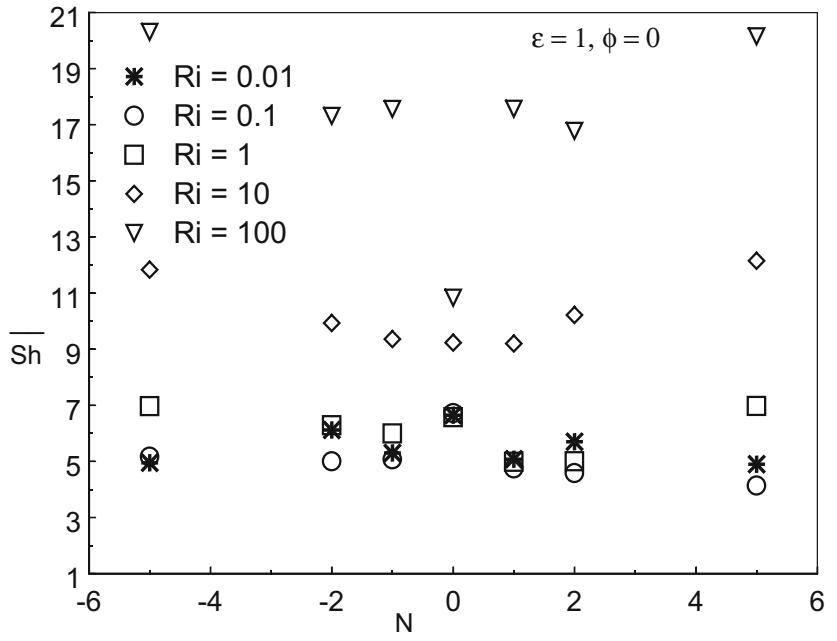

(b)

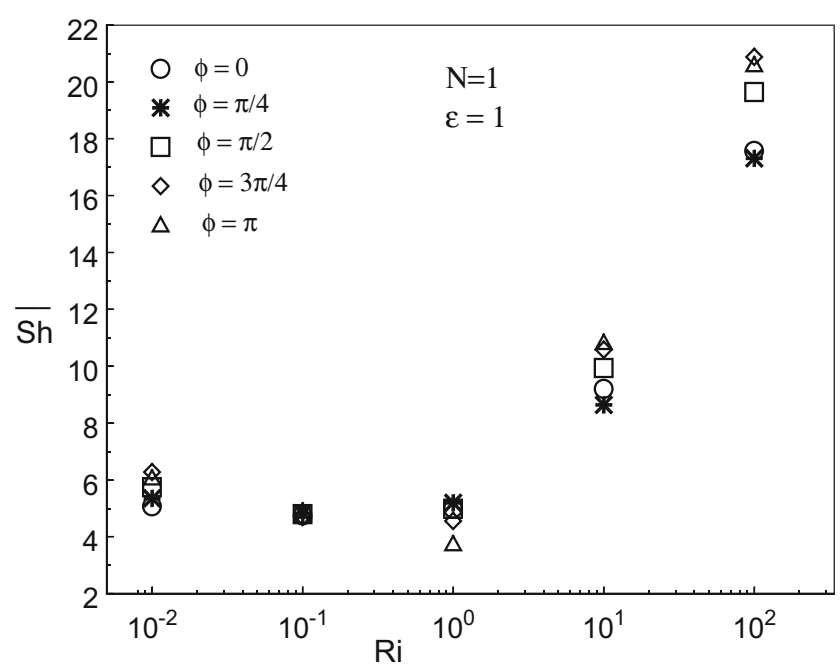

(d)

Figure 7. Average Sherwood number for different values of $N$ and $R i$ with different values of $\varepsilon$ and $\varphi$.

- The heat and mass transfer rates behaves non-linearly with buoyancy ratio parameter and phase deviation of the wall temperature.

- Non-uniform heating on both sidewalls enhances heat and mass transfer rates more than that of non-uniform heating on one sidewall.

- The heat transfer rate increases with the amplitude of the wall temperature. However, mass transfer is not affected much with the amplitude.

- The heat transfer is enhanced at $\phi=3 \pi / 4$ in the natural convection mode and at $\phi=\pi / 2$ in the forced convection mode.

- The overall mass transfer rate gradually decreased on increasing the amplitude ratio in forced convection regime, whereas it increased in the free convection mode on increasing the amplitude ratio from 0 to 1 .

- Both average Nusselt and Sherwood numbers are strongly affected in the natural convection mode than that in forced and mixed convection regimes.

\section{List of symbols}

A amplitude

c concentration $\left(\mathrm{kg} / \mathrm{m}^{3}\right)$

C dimensionless concentration

$D \quad$ mass diffusivity $\left(\mathrm{m}^{2} / \mathrm{s}\right)$

$g \quad$ acceleration due to gravity $\left(\mathrm{m} / \mathrm{s}^{2}\right)$

$G r_{C}$ solutal Grashof number 
$G r_{T}$ thermal Grashof number

$L \quad$ length of the cavity (m)

$N \quad$ buoyancy ratio

$\mathrm{Nu}$ local Nusselt number

$\overline{\mathrm{Nu}}$ average Nusselt number

$p \quad$ pressure $(\mathrm{Pa})$

$P r \quad$ Prandtl number

Re Reynolds number

$R i \quad$ Richardson number

Sc Schmidt number

Sh local Sherwood number

$\overline{S h}$ average Sherwood number

$t$ time (s)

$T$ temperature (K)

$u, v \quad$ velocity components $(\mathrm{m} / \mathrm{s})$

$U, V$ dimensionless velocity components

$U_{0} \quad$ lid velocity $(\mathrm{m} / \mathrm{s})$

$x, y \quad$ Cartesian coordinates (m)

$X, Y$ dimensionless coordinates

\section{Greek symbols}

$\alpha \quad$ thermal diffusivity $\left(\mathrm{m}^{2} / \mathrm{s}\right)$

$\varepsilon \quad$ amplitude ratio

$\beta_{T}$ thermal expansion coefficient $(1 / \mathrm{K})$

$\beta_{c}$ solutal expansion coefficient $(1 / \mathrm{K})$

$v \quad$ kinematic viscosity $\left(\mathrm{m}^{2} / \mathrm{s}\right)$

$\tau$ dimensionless time

$\rho$ density $\left(\mathrm{kg} / \mathrm{m}^{3}\right)$

$\theta$ dimensionless temperature

$\psi \quad$ stream function $\left(\mathrm{m}^{2} / \mathrm{s}\right)$

$\Psi$ dimensionless stream function

$\omega$ vorticity (1/s)

$\varphi$ phase deviation

\section{Subscripts}

1 left wall/low

$r$ right wall

0 reference state

h high/hot

c cold

\section{References}

[1] Hemalatha K, Kameswaran P K and Madhavi M V D N S 2015 Mixed convective heat transfer from a vertical plate embedded in a saturated non-Darcy porous medium with concentration and melting effect. Sadhana 40(2): 455-465

[2] Sharma A K, Mahapatra P S, Manna N K and Ghosh K 2015 Mixed convection in a baffled grooved channel. Sadhana 40(3): 835-849

[3] Garimella S V and Simpson J E 2001 Effect of thermosolutal convection on directional solidification. Sadhana 26(1): $121-138$
[4] Joly F, Vasseur P and Labrosse G 2000 Soret-driven thermosolutal convection in a vertical enclosure. Int. Commun. J. Heat Mass Transf. 27(6): 755-764

[5] Sezai I and Mohamad A A 2000 Double diffusive convection in a cubic enclosure with opposing temperature and concentration gradients. Phys. Fluids 12(9): 2210-2223

[6] Chamkha A J and Al-Naser H 2002 Hydromagnetic doublediffusive convection in a rectangular enclosure with opposing temperature and concentration gradients. Int. J. Heat Mass Transf. 45: 2465-2483

[7] Al-Amiri A M, Khanafer K M and Pop I 2007 Numerical simulation of combined thermal and mass transport in a square lid-driven cavity. Int. J. Theor. Sci. 46: 662-671

[8] Sivasankaran S, Kandaswamy P and Ng C O 2008 Double diffusive convection of anomalous density fluids in a porous cavity. Transp. Porous Media 71(2): 133-145

[9] Teamah M A 2008 Numerical simulation of double diffusive natural convection in rectangular enclosure in the presences of magnetic field and heat source. Int. J Theor. Sci. 47: 237-248

[10] Bhuvaneswari M, Sivasankaran S and Kim Y J 2011 Numerical study on double diffusive mixed convection with a soret effect in a two-sided lid-driven cavity. Numer. Heat Transf. A 59: 543-560

[11] Ismael M A and Chamkha A J 2015 Mixed convection in liddriven trapezoidal cavities with an aiding or opposing side wall. Numer. Heat Transf. A 68: 312-335

[12] Wang J, Yang M and Zhang Y 2015 Coupling-diffusive effects on thermosolutal buoyancy convection in a horizontal cavity. Numer. Heat Transf. A 68: 583-597

[13] Saeid N H and Yaacob Y 2006 Natural convection in a square cavity with spatial side-wall temperature variation. Numer. Heat Transf. A 49: 683-697

[14] Basak T, Roy S and Takhar H S 2007 Effects of non-uniformly heated wall(s) on a natural convection flow in a square cavity filled with a porous medium. Numer. Heat Transf. A 51: 959-978

[15] Deng Q H and Chang J J 2008 Natural convection in a rectangular enclosure with sinusoidal temperature distributions on both side walls. Numer. Heat Transf. A 54: 507-524

[16] Sivasankaran S, Sivakumar V and Prakash P 2010 Numerical study on mixed convection in a lid-driven cavity with nonuniform heating on both sidewalls. Int. J. Heat Mass Transf. 53: 4304-4315

[17] Bhuvaneswari M, Sivasankaran S and Kim Y J 2011 Magneto-convection in an enclosure with sinusoidal temperature distributions on both side walls. Numer. Heat Transf. A 59: 167-184

[18] Sivasankaran S, Malleswaran A, Lee J and Sundar P 2011 Hydro-magnetic combined convection in a lid-driven cavity with sinusoidal boundary conditions on both sidewalls. Int. J. Heat Mass Transf. 54: 512-525

[19] Aswatha G, Gowda C J, Sridhara S N and Seetharamu K N 2012 Buoyancy driven heat transfer in cavities subjected to thermal boundary conditions at bottom wall. J. Appl. Fluid Mech. 5(2): 43-53

[20] Singh A K, Roy S and Basak T 2012 Visualization of heat transport during natural convection in a tilted square cavity: effect of isothermal and non-isothermal heating. Numer. Heat Transf. A 61: 417-441 
[21] Sivasankaran S and Pan K L 2012 Numerical simulation on mixed convection in a porous lid-driven cavity with nonuniform heating on both sidewalls. Numer. Heat Transf. A 61(2): 101-121

[22] Raji A, Hasnaoui M, Firdaouss M and Ouardi C 2013 Natural convection heat transfer enhancement in a square cavity periodically cooled from above. Numer. Heat Transf. A 63: 511-533

[23] Sivasankaran S and Bhuvaneswari M 2013 Natural convection in a porous cavity with sinusoidal heating on both sidewalls. Numer. Heat Transf. A 63(1): 14-30

[24] Sivakumar V and Sivasankaran S 2014 Mixed convection in an inclined lid-driven cavity with non-uniform heating on both side walls. J. Appl. Mech. Tech. Phys. 55(4): 634-649

[25] Sivasankaran S and Pan K L 2014 Natural convection of nanofluids in a cavity with non-uniform temperature distributions on side walls. Numer. Heat Transf. A 65: 247-268

[26] Sharif M A R 2007 Laminar mixed convection in shallow inclined driven cavities with hot moving lid on top and cooled from bottom. Appl. Therm. Eng. 27: 1036-1042

[27] Iwatsu R, Hyun J M and Kuwahara K 1993 Mixed convection in a driven cavity with a stable vertical temperature gradient. Int. J. Heat Mass Transf. 36: 1601-1608 